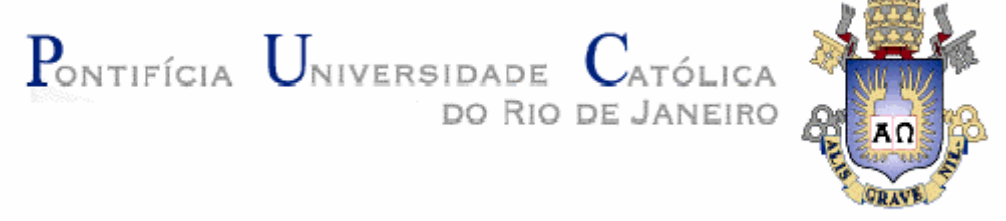

Vinicius Teixeira Santos

\title{
Letramento em História e Formação Docente nos Cursos Pré-Vestibulares Comunitários (CPVCs): os espaços de mediações político-pedagógicas
}

Dissertação apresentada como requisito parcial para obtenção do grau de Mestre pelo Programa de Pós-Graduação em Educação do Departamento de Educação da PUC-Rio.

Orientador: Prof. José Carmello Braz de Carvalho 


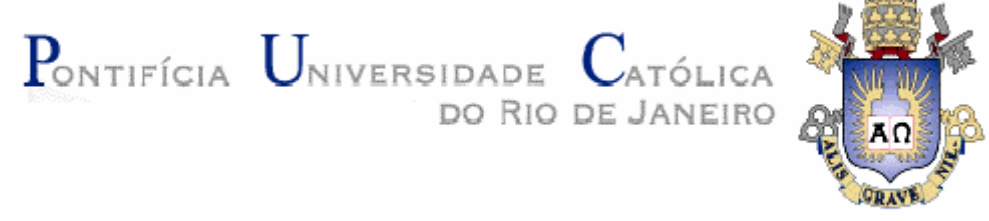

Vinicius Teixeira Santos

\section{Letramento em História e Formação Docente nos Cursos Pré-Vestibulares Comunitários (CPVCs): os espaços de mediações político-pedagógicas}

Dissertação apresentada como requisito parcial para obtenção do grau de Mestre pelo Programa de Pós-Graduação em Educação do Departamento de Educação do Centro de Teologia e Ciências Humanas da PUC-Rio. Aprovada pela Comissão Examinadora abaixo assinada.

Prof. José Carmello Braz de Carvalho

Orientador

Departamento de Educação - PUC-Rio

Prof. José Maurício Paiva Andion Arruti

Departamento de Educação - PUC-Rio

Prof. Paulo Cavalcante de Oliveira Junior

UERJ

Prof. Paulo Fernando C. de Andrade Coordenador Setorial do Centro de Teologia e Ciências Humanas

Rio de Janeiro, 09 de abril de 2008. 
Todos os direitos reservados. É proibida a reprodução total ou parcial do trabalho sem autorização da universidade, da autora e do orientador.

\section{Vinicius Teixeira Santos}

Vinicius Teixeira Santos, professor, Bacharel e Licenciado em História pela Universidade Federal Fluminense (UFF-RJ), em 2002. Leciona História desde 2002 no Ensino Fundamental, vinculado à Secretaria de Educação da Prefeitura Municipal de Cabo Frio (RJ). Desde 1998 atua como professor e coordenador do Pré-vestibular para Negros e Carentes, núcleo FEUDUC (PVNC-FEUDUC), em Duque de Caxias no Rio de Janeiro. Concluiu em 2006 o curso de Especialização em Supervisão Escolar, na Universidade Candido Mendes (UCAM-RJ). Pela Pontifícia Universidade Católica do Rio de Janeiro ( PUC-Rio) obteve o Mestrado em Educação Brasileira, em 2008 .

Ficha Catalográfica

Santos, Vinicius Teixeira

Letramento em História e formação docente nos Cursos Pré-vestibulares Comunitários (CPVCs): os espaços de mediações político-pedagógicas / Vinicius Teixeira Santos ; orientador: José Carmello Braz de Carvalho. - 2008.

$166 \mathrm{f}$; $30 \mathrm{~cm}$

Dissertação (Mestrado em Educação) - Pontifícia Universidade Católica do Rio de Janeiro, Rio de Janeiro, 2008.

Inclui bibliografia.

1. Educação - Teses. 2. Letramento em história. 3. Formação de professores. 4. Matriz do ENEM. I. Carvalho, José Carmello Braz de. II. Pontifícia Universidade Católica do Rio de Janeiro. Departamento de Educação. III. Título. 
Dedico este trabalho à multidão de anônimos que gestam a esperança de uma sociedade melhor e mais justa, em especial ao PVNC Núcleo-Feuduc. 


\section{Agradecimentos}

Qualquer sombrinha me refresca.

Guimarães Rosa

Qualquer um que leva a vida nessaestrada

Só precisa de uma sombra pra chegar.

Fagner

Minha trajetória humana, acadêmica e profissional se expressa radicalmente como uma produção coletiva. Fazemos escolhas a partir das contingências da vida, e seus resultados não são previsíveis, apenas vislumbrados. Um olhar através do retrovisor da História nos permite compreender melhor os percalços da caminhada, e como muitas pessoas são essenciais para nos abrigar nas sombras produzidas por suas existências. Mesmo arriscando esquecer alguém, não posso deixar de citar algumas das pessoas que a vida me ensinou serem especiais. E então agradeço a Deus, por me permitir que nossos caminhos se cruzassem.

A presente pesquisa só foi possível devido à colaboração direta e indireta de várias pessoas, como os professores Paulo Cavalcante, Rosália Duarte, Eliane Vinhaes, a quem muito agradeço, assim como ao Departamento de Educação da PUC-Rio, por me possibilitar cursar o Mestrado, concedendo-me uma bolsa de isenção. Meu especial agradecimento ao professor e orientador José Carmelo Braz de Carvalho, pelo apoio e incentivo sempre presentes, sem os quais as tensões da travessia jamais teriam sido atenuadas.

Agradeço aos colegas de turma, em especial a Beth Lima e Vanessa Portella, com quem foram compartilhadas angústias e tensões produzidas ao longo do Curso de Mestrado. Sou grato, também, aos amigos e colegas das escolas em que trabalho, em especial Claudia Teresinha, Etiani Gambeta. Machado, Luciana Espíndola Botelho e Verônica Cardozo.

Agradeço a minha família, especialmente Natanaelia e ao Luis, pelo apoio incondicional, e aos amigos Osmar Santos, Rogério Peixoto, Roberta Silva, Paula Patrícia, Danielle Reis, José Carlos, Marília Campos, Heliomar Kann, Anderson Augusto, Leandro Dias, Luciane Correa, Tatiane Correa, Ricardo Diego, Amarilis Porto, Rondinelle Moutta, Juliana Santana e Marta Abreu, pois suas mediações produzem efeitos continuamente; afinal, a docência tem impactos que não são mensuráveis, sobre a vida dos alunos. Sou imensamente grato a Isabella Vargas, companheira de labuta, por dissipar a sensação de solidão de alguns momentos da caminhada, e a Caroline Moraes, pela interlocução, pelo companheirismo, e por me ensinar que ler nunca é uma atividade simples. Meu agradecimento, também, à professora Ledda Maria Dias, pela revisão e por sua generosidade, essenciais para o término deste trabalho. 


\section{Resumo}

Santos, Vinícius Teixeira; Carvalho, José Carmello Braz de. Letramento em história e formação docente nos Cursos Pré-vestibulares Comunitários (CPVCs): os espaços de mediações pedagógicas. Rio de Janeiro, 2008, 166 p. Dissertação de Mestrado - Departamento de Educação, Pontifícia Universidade Católica do Rio de Janeiro.

A dissertação analisa a formação de professores de CPVCs, articulada ao desenvolvimento das habilidades e competências leitoras, na perspectiva do Letramento em História. O quadro teórico reporta-se a dois eixos de fundamentação: na perspectiva do Letramento em História, apóia-se em autoras como Isabel Barca, Vitória Rodrigues Silva e Magda Soares, ao analisar o conceito de Letramento; já na perspectiva epistemológica, Paulo Freire e Vygotsky respaldam as concepções de mediação no desenvolvimento dos conhecimentos e processos psicológicos mais complexos, em uma abordagem dinâmica que remete à inter-relação entre os indivíduos. Como estudo de campo, é analisada a prática formativa de docentes de História associados a CPVCs, em cursos programados durante o biênio 2006-2007, com base na matriz de competências e habilidades do ENEM, em uma proposta histórico-cultural de base paulofreireana. São utilizados recursos técnico-metodológicos de análise documental sobre os materiais curriculares e didáticos (apostilas e avaliações formativas), bem como entrevistas semi-estruturadas com os professores formadores do Curso de Capacitação de Professores dos CPVCs. Observações de interlocuções entre os cursistas dos CPVCs e a equipe docente, e avaliações formuladas pelos cursistas sobre a avaliação formativa desenvolvida em suas classes comunitárias complementam os recursos. Diante da escassa produção acadêmica sobre as questões teórico-práticas de Letramento em História, em CPVCs, segundo a Matriz de Competências do ENEM “mediatizada” por aportes do paradigma histórico-cultural com base em Paulo Freire e Vygotsky, ressalta-se que: i) os processos formativos da leitura em História e suas habilidades e competências ocorrem de forma orientada pelo professor de História; ii) a Matriz de Competências do ENEM não se traduz em empecilho para o desenvolvimento do conhecimento histórico; antes, ao diminuir as tensões derivadas da acumulação estéril de informações, tão cara ao vestibular, pode possibilitar um trabalho pedagógico mais substantivo, por parte dos professores de História; iii) o desenvolvimento das capacidades de leitura é parte constitutiva do conhecimento histórico, e não mero anexo para facilitar a apropriação de informações de fatos e acontecimentos da História; iv) o Letramento em História pressupõe o desenvolvimento de competências e habilidades de leitura que considere os suportes textuais como portadores de questões políticas, ideológicas, culturais, sociais e econômicas, ou seja, os suportes não são neutros. Ser letrado em História, desta forma, significa desenvolver continuamente a capacidade de realizar a leitura histórica do mundo e a finitude das suas formações sociais.

\section{Palavras-chave:}

Letramento em História, Formação de Professores, Matriz do ENEM. 


\section{Abstract}

Santos, Vinícius Teixeira; Carvalho, José Carmello Braz de (Advisor). History Literacy and Teachers Training in CPVCs, as spaces of pedagogical mediations in poor metropolitan areas classrooms. Rio de Janeiro, 2008, 166 p. MSc. Dissertation - Departamento de Educação, Pontifícia Universidade Católica do Rio de Janeiro.

The dissertation analyses the process of training voluntary teachers in CPVCs, as self sustained community classes in poor metropolitan areas, preparing for university entrance examinations. History literacy is aimed at the development of competences and abilities in reading at the final level of high school. The dissertation theoretical frame-wok is based on Isabel Barca, Vitória Rodrigues Silva and Magda Soares` literacy concept; as well as in Freire and Vygotsky`s epistemology in relation to the mediations implied in the development of complex psychological processes. The field research analyses the teachers training programs in CPVCs in 2006-2007, based on a constructivism matrix for the development of high school competences, articulated to a proposal of historicalcultural approach based on Paulo Freire. The research data were gathered through archival studies on curriculum and didactic materials developed in the 2006-2007 trainings; and on semi-structured interviews, on field observations, as well as on formative evaluations carried in CPVCs classrooms. The main conclusions are: i) the History literacy process, articulating the constructivism matrix to Freire and Vygotsky historical-cultural approach, may be oriented by History teachers; ii) the constructivism competences matrix does not undermine the development of historical knowledge; therefore it may allow a more substantive teaching training program; iii) indeed the reading competences development is a constitutive part of historical knowledge; hence it is not a simple device to gather information about History; iv) the History literacy requires reading competences and abilities, based on several textual supporters, that are not neutral materials in relation to political, ideological and social problems. Hence being literate in History implies a continuous development of the competence to read the social and historical world, and the perception of finitude of the social formations.

\section{Key-words:}

History Literacy, Teachers Training, Reading Competences Matrix. 


\section{Sumário}

1. Introdução

2. Caracterização da questão e desenvolvimento de um quadro de referência ... 18

2.1. Panorama sobre o ensino de História ...................................................... 18

2.1.1. Historiando a História como disciplina escolar secundarista ................... 19

2.1.2. Alguns percursos da História ensinada no Ensino Médio ......................... 22

2.1.3. Ensino de História a partir dos anos 80: breve balanço........................... 33

2.2. Letramento em História ................................................................. 41

2.2.1. Contribuições teórico-práticas do paradigma histórico-cultural ................ 44

2.2.2. A idéia de Letramento em História .............................................. 53

2.3. Formação docente: um olhar a partir da perspectiva histórico-cultural ......... 59

2.3.1. Considerações sobre a formação docente do professor de História .......... 63

3. Contextualização sobre a formação docente em História nos CPVCs ............ 65

3.1. Cursos Pré-vestibulares Comunitários (CPVCs) .................................67 67

3.2. Da tradição propedêutica de exames vestibulares a uma proposta de formação docente segundo a Matriz de Competências e Habilidades do ENEM 73 3.3. Uma alternativa de formação docente nos CPVCs segundo Pedro e Marta . 81

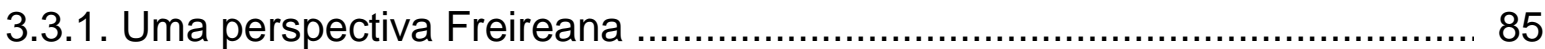

3.4. Delineamentos de um quadro conceitual-empírico para pesquisa ............... 88

4. Análise do material conceitual-empírico coletado ...................................... 91

4.1. Práticas e formação no ensino de História ............................................ 92

4.2. Marta: uma memória de muitas tramas ............................................. 93

4.2.1. Algumas reflexões sobre a experiência docente ................................... 94

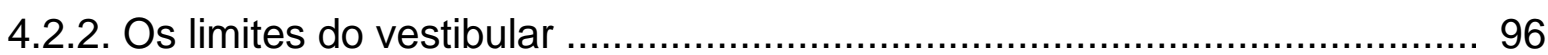

4.2.3. Sobre o Curso de Capacitação ...................................................... 99

4.3. Pedro: de corpo e alma no magistério ............................................ 102 
4.3.1. Críticas ao vestibular 104

4.3.2. A especificidade do saber histórico e o curso de capacitação ................... 105

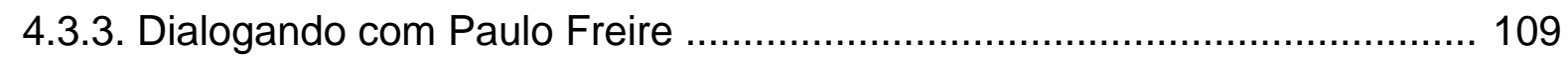

4.4. Mapeamento das implicações conceituais e operacional-empíricas das questões do Simulado do ENEM 2006, junto aos CPVCs

4.4.1. Analisando as implicações conceitual-empíricas das "questões de História" 121

4.5. Avaliações Formativas de História 128

4.6. Reconstrução das questões do ENEM Simulado em articulação às bases epistemológicas paulofreireanas 131

4.7. A título de conclusões da pesquisa 135

5. Considerações Finais 140

5.1. Letramento em História e ENEM: desafios, tensões e possibilidades 140

6. Referências Bibliográficas 146

Anexos 154 
Quem construiu Tebas, a das sete portas?

Nos livros vem o nome dos reis, Mas foram os reis que transportaram as pedras?

Babilônia, tantas vezes destruída, Quem outras tantas a reconstruiu? Em que casas

Da Lima Dourada moravam seus obreiros? No dia em que ficou pronta a Muralha da China para onde Foram os seus pedreiros? A grande Roma Está cheia de arcos de triunfo. Quem os ergueu? Sobre quem Triunfaram os Césares? A tão cantada Bizâncio

Só tinha palácios

Para os seus habitantes? Até a legendária Atlântida Na noite em que o mar a engoliu Viu afogados gritarem por seus escravos.

O jovem Alexandre conquistou as Índias Sozinho?

César venceu os gauleses.

Nem sequer tinha um cozinheiro ao seu serviço? Quando a sua armada se afundou, Filipe de Espanha Chorou. E ninguém mais?

Frederico II ganhou a guerra dos sete anos Quem mais a ganhou?

Em cada página uma vitória.

Quem cozinhava os festins? Em cada década um grande homem.

Quem pagava as despesas?

Tantas Histórias

Quantas perguntas

Perguntas de um Operário Que Lê, Bertold Brecht 